\title{
Rotulagem de alimentos para lactentes e crianças de primeira infância
}

\author{
Labeling food products for breastfeeding \\ infants and toddlers
}

Sheylle Almeida da SILVA

Márcia Regina de Moura DIAS²

Tânia Aparecida Pinto de Castro FERREIRA ${ }^{1}$

\section{RE S U M O}

\section{Objetivo}

Analisar a conformidade de rótulos de alimentos para lactentes e crianças de primeira infância, segundo os preceitos da ética e das legislações vigentes.

\section{Métodos}

Foram analisados 86 rótulos captados por livre acesso, amostragem intencional, distribuídos em: fórmulas infantis para lactentes $(n=11)$, fórmulas de seguimento para lactentes $(n=5)$; alimentos de transição $(n=7)$; alimentos à base de cereais $(n=11)$, leites e alimentos à base de vegetais $(n=52)$ e alimentos comuns usualmente empregados na alimentação desse público $(n=13)$. Foram preenchidos formulários estruturados com itens das Resoluções da Diretoria Colegiada 222/02, 977/98, 40/01, 40/02, 259/02, 23/00 e das Portarias 34/98 e 36/98 para cada alimento. Aplicaram-se os Testes Qui-Quadrado, Exato de Fisher e de Correlação.

\section{Resultados}

A freqüência de não conformidades na rotulagem específica foi muito maior que na rotulagem geral. A maior freqüência de não conformidades observada foi a apresentação de ilustrações inadequadas nos alimentos (imagens de lactentes ou crianças com figuras humanizadas). Outras inconformidades foram: a presença de expressões como leite humanizado, baby ou frases que dão falsa idéia de vantagem ou segurança; e a ausência de frases obrigatórias e não conformidade quanto à composição do produto. Alimentos que não tinham como designação de venda nenhuma das características de uso comum nesta faixa etária, ou seja, não eram comercializados como tal, como farinha láctea, flocos de cereais e mingaus, apresentavam frases de advertência não necessárias para aquele tipo de produto.

\section{Conclusão}

A rotulagem de alimentos para lactentes e crianças de primeira infância apresenta muitas irregularidades, principalmente no que se refere à rotulagem específica do produto. Essa prática pode repercutir sobre a

${ }^{1}$ Universidade Federal de Goiás, Faculdade de Nutrição. R. 227, Qd. 68, s/n., Prédio FANUT/FEN, Setor Leste Universitário, 74605-080, Goiânia, GO, Brazil. Correspondencia para/Correspondence to: T.A.P.C. FERREIRA. E-mail: <tania@fanut.ufg.br>.

2 Secretaria de Vigilância Sanitária e Ambiental do Estado de Goiás. Goiânia, GO, Brasil. 
186 S.A. SILVA et al.

amamentação. A fiscalização deve ser intensificada, conjuntamente com maiores esclarecimentos às indústrias de alimentos e aos consumidores em geral.

Termos de indexação: Aleitamento materno. Fórmulas infantis. Promoção de alimentos. Rotulagem de alimentos. Substitutos do leite humano.

\section{A B S T R A C T}

\section{Objective}

The objective of the study was to analyze label conformity of foods for infants and lactating women according to ethical principles and current regulations.

\section{Methods}

A total of 86 labels acquired by free access and intentional sampling were analyzed, distributed as follows: infant formulas $(n=11)$, follow-on formulas $(n=5)$, complementary foods $(n=07)$, cereal products $(n=11)$, milk and foods containing vegetables $(n=52)$, and food commonly used to feed this population $(n=13)$. Structured forms were filled out with items from the Resoluções da Diretoria Colegiada (Graduated Board Resolutions) 222/02, 977/98, 40/01, 40/02, 259/02, 23/00 and of the Portarias (rules) 34/98 and 36/98 for each food. The chi-square test, Fisher's exact test and correlation test were used for data analysis.

\section{Results}

The rate of specific label non-conformity was much greater than that of general labeling. The highest rate of non-conformity was observed in the presentation of illustrations of the foods (images of breastfeeding infants or children with humanized images). Other non-conformities were: the presence of words such as humanized milk, baby or phrases that give a false idea of advantage or safety; the absence of mandatory phrases and non-conformity regarding the composition of the food. Foods that did not have as sales designation any of the characteristics of common use in this age group, that is, that were not marketed as such, such as lacteal flour, cereal flakes and paps presented warning phrases that were not necessarily for that kind of product.

\section{Conclusion}

Labels of foods for breastfeeding infants and toddlers are irregular in many ways, especially regarding the specific labeling of the product. This practice may influence breastfeeding. More inspection is needed as well as more explanations to the food industries and to the consumers in general.

Indexing terms: Breast feeding. Infant formula. Food promotion. Food labeling. Breast-milk substitutes.

\section{N T R O D U Ç Ã O}

Até o final da era pré-industrial, a alimentação do lactente era realizada exclusivamente com leite materno e, na impossibilidade de a criança ser amamentada pela própria mãe, isso, geralmente, era feito pela ama ou avó ${ }^{1}$.

O primeiro registro encontrado da substituição do leite humano na alimentação infantil é de 1784, quando um médico inglês indicou como alternativa alimentar o leite de vaca².

Com a industrialização e com a incorporação da mão-de-obra feminina no mercado de trabalho, a indústria de alimentos desenvolveu vários produtos para lactentes e crianças de primeira infância1,2. Estes foram, até então, vendidos pela estratégia da imagem construída de um produto perfeito, conveniente e permissivo da participação do pai na alimentação da criança ${ }^{3}$. Alegações como: o leite materno é fraco ou não fornece todos os nutrientes necessários ao ótimo crescimento e desenvolvimento do bebê; ou que o substituto do leite materno ofereceria maior praticidade à mãe, foram utilizadas².

Essa situação contribuiu para diminuir as taxas de aleitamento materno exclusivo em todo o mundo ${ }^{1}$ e para o aumento dos índices de morbimortalidade infantil nos países pobres e de morbidade nos países ricos ${ }^{1}$. Estudo mostra aumento progressivo da prevalência de doenças digestivas, 
respiratórias e de alergias, entre outras, nas crianças que se alimentaram exclusivamente com fórmulas industrializadas ${ }^{1}$.

Nas décadas de 70 e 80 iniciou-se um processo de conscientização a respeito do uso de Sucedâneos do Leite Materno (SLM) sobre o desmame precoce, e particularmente, sobre sua promoção comercial de maneira não ética. A partir de 1981, a Organização Mundial da Saúde (OMS) passou a recomendar, junto com o United Nations Children's Fund (UNICEF), o Código Internacional de Comercialização de Substitutos do Leite Materno ${ }^{4}$. Em maio de 2001, foi aprovada a Estratégia Global para a Alimentação Infantil ${ }^{5}$, que recomenda a promoção do aleitamento materno exclusivo para, praticamente, todos os lactentes até seis meses de vida e a introdução, a partir dessa idade, de alimentos complementares nutricionalmente adequados, inócuos e culturalmente apropriados, acompanhada de amamentação continuada por, pelo menos, dois anos.

No Brasil foram aprovadas regulamentações com os objetivos de promover a adequada nutrição dos lactentes e evitar os riscos associados à não amamentação, muitas vezes fomentada pela promoção comercial de SLM. Em 1992, foi aprovada a Norma Brasileira para Comercialização de Alimentos para Lactentes (NBCAL) ${ }^{6}$, que regulamenta a comercialização desses alimentos. Em 2002, a Agência Nacional de Vigilância Sanitária (ANVISA) aprovou a resolução da diretoria colegiada (RDC) $n^{\circ} 222^{7}$, que normatiza a promoção, comercialização e rotulagem dos alimentos para lactentes e crianças de primeira infância.

Legislações que visam à proteção e ao incentivo à amamentação representam avanço significativo para a saúde deste público. Contudo, sabe-se que o contingente de fiscais da Vigilância Sanitária é pequeno ${ }^{8}$ para a realização da fiscalização de todos esses produtos.

Este trabalho tem como objetivo analisar a rotulagem de produtos alimentícios comercializados para lactentes e crianças de primeira infância, com vistas a contribuir para a promoção de práticas saudáveis relacionadas à alimentação de lactentes e crianças de primeira infância.

\section{MÉ T O D O S}

Foram analisados 86 rótulos de alimentos designados como "alimento para lactentes e crianças de primeira infância", classificados nas seguintes categorias: (I) Fórmulas infantis para lactentes (item 1.2.1 da Resolução a Diretoria Colegiada (RDC) n 222/027; Portaria n 977/98 ${ }^{9}$ ); (II) Fórmulas infantis de seguimento para lactentes (item 1.2.1 da Resolução RDC n 222/027; Portaria no 977/989); (III) Leites de vaca (fluido, em pó ou em pó modificado), leites de cabra (em pó ou fluido) e alimentos à base de soja (em pó ou fluido) (item 1.2.4 da Resolução RDC $n^{\circ} 222 / 02^{7}$ ); (IV) Alimentos de transição indicados para lactentes e/ou crianças de primeira infância (sopinhas e papinhas) (item 1.2.4 da Resolução RDC n 222/027; Portaria $\left.n^{0} 34 / 98^{10}\right)$; (V) Alimentos à base de cereais indicados para lactentes e/ou crianças de primeira infância (item 1.2.4 da Resolução $\mathrm{n}^{\circ}$ 222/027; Portaria no $n^{\circ} 36 / 98^{11}$ ); (VI) Alimentos comuns, sem, inclusive, necessidade de registro, mas freqüentemente utilizados na alimentação de lactentes ou crianças de primeira infância.

A análise da rotulagem geral de todas as categorias acima contemplou os itens: presença da designação do produto no painel principal (itens 9.1 da Portaria n 977/989); identificação das fontes protéicas no rótulo (item 9.1.3 da Port. n 977/989); presença de rotulagem nutricional de acordo com a Resolução RDC n 40/0112; apresentação das informações em português (Resolução RDC $n^{\circ}$ 259/02 $\left.{ }^{13}\right)$; presença de lista de ingredientes, apresentação de conteúdo líquido, identificação da origem, identificação do lote e do prazo de validade (item 5 da Resolução RDC n 259/02 ${ }^{13}$ ); presença do registro no Ministério da Saúde (Resolução RDC n ${ }^{\circ}$ 23/0014); apresentação da expressão "Contém Glúten", se houver na composição cevada, centeio, aveia, trigo e/ou malte (Resolução RDC nº 40/02 ${ }^{15}$ )

Quanto à rotulagem específica, exceto para a categoria VI, foram contemplados os seguintes aspectos:

- Presença de ilustrações não conformes (itens 4.3.1, 4.10.1 e 4.12.1 da Res. RDC $\left.n^{\circ} 222 / 02^{6}\right)$; 
- Frases que sugerissem forte semelhança do produto com o leite humano (apenas para as categorias I, II e III dos itens 4.3.2, 4.10.2 da Res. RDC $\left.n^{\circ} 222 / 02^{6}\right)$;

- Frases que colocassem em dúvida a capacidade das mães amamentarem (itens 4.3.3, 4.10.3 e 4.12.2 da Resolução RDC n 222/02 ${ }^{6}$ );

- Denominações que identificassem o produto como apropriado para lactente menor de seis meses de idade (itens 4.3.4, 4.10.4 e 4.12.3 da Resolução RDC n 222/02 ${ }^{6}$ );

- Informações caracterizadas como falso conceito de vantagem ou segurança (itens 4.3.5, 4.10.5 e 4.12.4 da Resolução RDC n²222/026);

- Presença de promoção de outros produtos no rótulo (itens 4.3.7, 4.10.6 e 4.12.5 da Resolução RDC $\left.n^{\circ} 222 / 02^{6}\right)$;

- Expressões que indicassem condições de saúde para as quais o produto pudesse ser usado (item 4.3.6 da Resolução RDC n 222/026);

- Presença das frases de advertência obrigatórias (itens 4.4, 4.11.1, 4.11.2 e 4.14 da Resolução RDC n²22/026);

- Apresentação visual correta das frases de advertência obrigatórias (itens 4.11 da Resolução e 4.14 da Resolução RDC $n^{\circ} 222 / 02^{6}$ );

- Frases de advertência obrigatórias relativas à composição dos produtos abaixo (itens 9.2, 4.1.1 e 4.12. da Portaria 34/98 ${ }^{10}$, itens 4.1 .7 e 9.6 da Portaria 36/98 ${ }^{11}$, Res. RDC no 40/02 ${ }^{15}$ ):

- Produtos elaborados com cevada, centeio, aveia, trigo e/ou malte devem apresentar a expressão "Contém Glúten".

- Fórmulas infantis para lactentes e fórmulas infantis de seguimento para lactentes em produto sem leite ou derivado lácteo, devem identificar fontes protéicas e apresentar a frase "Não contém leite e/ou produtos lácteos" ou frase equivalente.

- Alimentos de transição, elaborados com espinafre ou beterraba devem exibir a expressão "Contém espinafre e/ou beterraba. Não pode ser consumido por menores de 3 meses de idade".
- Alimentos de transição, elaborados à base de frutas, não podem ter adição de sal.

- Alimentos de transição e alimentos à base de cereais, elaborados com gema de ovo devem apresentar indicação para crianças acima de 10 meses de idade;

- Alimentos de transição e alimentos à base de cereais, elaborados com cacau, devem apresentar indicação de que o consumo só é apropriado para crianças acima de 9 meses de idade;

- Presença de advertências quanto ao preparo inadequado e instruções para o preparo adequado (item 4.5 da Resolução RDC n ${ }^{\circ} 222 / 02^{6}$ e item 9.3 da Portaria ${ }^{\circ} 36 / 98^{11}$ ).

Para a análise da categoria VI, adaptou-se o formulário para alimentos à base de cereais. Foram analisadas a presença de ilustrações e fotos proibidas; frases ou expressões que colocassem em dúvida a capacidade das mães amamentarem seus filhos; denominações que identificassem o produto como apropriado para lactente menor de 6 meses de idade, tais como baby ou similares; informações que induzissem o uso do produto, baseadas em falso conceito de vantagem ou segurança e promoção de produtos da mesma empresa ou de outras empresas, correspondendo, respectivamente, aos itens 4.12.1, 4.12.2, 4.12.3, 4.12.4 e 4.12.5 da Resolução RDC n 222/02 ${ }^{6}$.

O critério adotado para a amostragem foi o livre acesso, com amostragem intencional, ou seja, foram coletados todos os produtos que tinham a designação de venda ou registro direcionados ao público alvo comercializados em Goiânia (GO), aos quais os pesquisadores tiveram acesso. Os rótulos analisados foram coletados a partir de trabalhos acadêmicos ou em parceria com a Superintendência de Vigilância Sanitária e Ambiental do Estado de Goiás/Brasil.

Foram utilizados formulários estruturados pelo Ministério da Saúde em 2002, e apresentados no Manual do Curso da Norma Brasileira de Comercialização de Alimentos para Lactentes e Crianças de Primeira Infância, Bicos Chupetas e Mamadeiras $^{16}$. 
Para comparar a freqüência esperada de rótulos conformes e não conformes na rotulagem específica com os da rotulagem geral, foram aplicados os testes estatísticos Exato de Fisher, Qui-Quadrado e de Correlação. Os rótulos classificados como não conformes foram aqueles que estavam em desacordo com, no mínimo, um item analisado.

Aplicou-se o Teste Exato de Fisher para as categorias que atendiam às condições de teste $(20<n<40$ e freqüência esperada menor que 5$)$ : fórmulas infantis para lactentes, leites e alimentos à base de cereais. Para as outras categorias, quando a freqüência esperada foi maior que 5, aplicou-se o Teste Qui-Quadrado. Ambos os testes consideraram significante valor de $p$ menor ou igual a 0,05.

O Teste de Correlação foi aplicado para analisar o grau de associação entre o número de produtos comercializados por três empresas que mais comercializam esses tipos de produto, e portanto, tiveram mais rótulos analisados, e o número de não conformidades observadas. Excluíram-se os alimentos de transição, por serem estes alimentos comercializados apenas por uma empresa.

\section{RE S U L T A D O S}

Quanto às exigências da rotulagem geral, observaram-se apenas dois produtos não conformes: um produto à base de cereais não apresentou o registro do Ministério da Saúde e um leite não exibiu o número do lote.

Em relação à legislação específica para rotulagem de alimentos para lactentes e crianças de primeira infância, observaram-se diversas não conformidades. A Figura 1 apresenta o número de rótulos não conformes nos diferentes itens analisados para as diversas categorias.

Os itens 4.3.1, 4.10.1 e 4.12.1 da Resolução RDC n ${ }^{\circ} 222 / 02^{6}$ proíbem o uso de ilustrações, fotos ou outras representações gráficas de lactentes, crianças pequenas ou figuras humanizadas. As ilustrações não conformes observadas nos rótulos analisados foram: ninho de pássaros com filhotes nas fórmulas infantis para lactentes

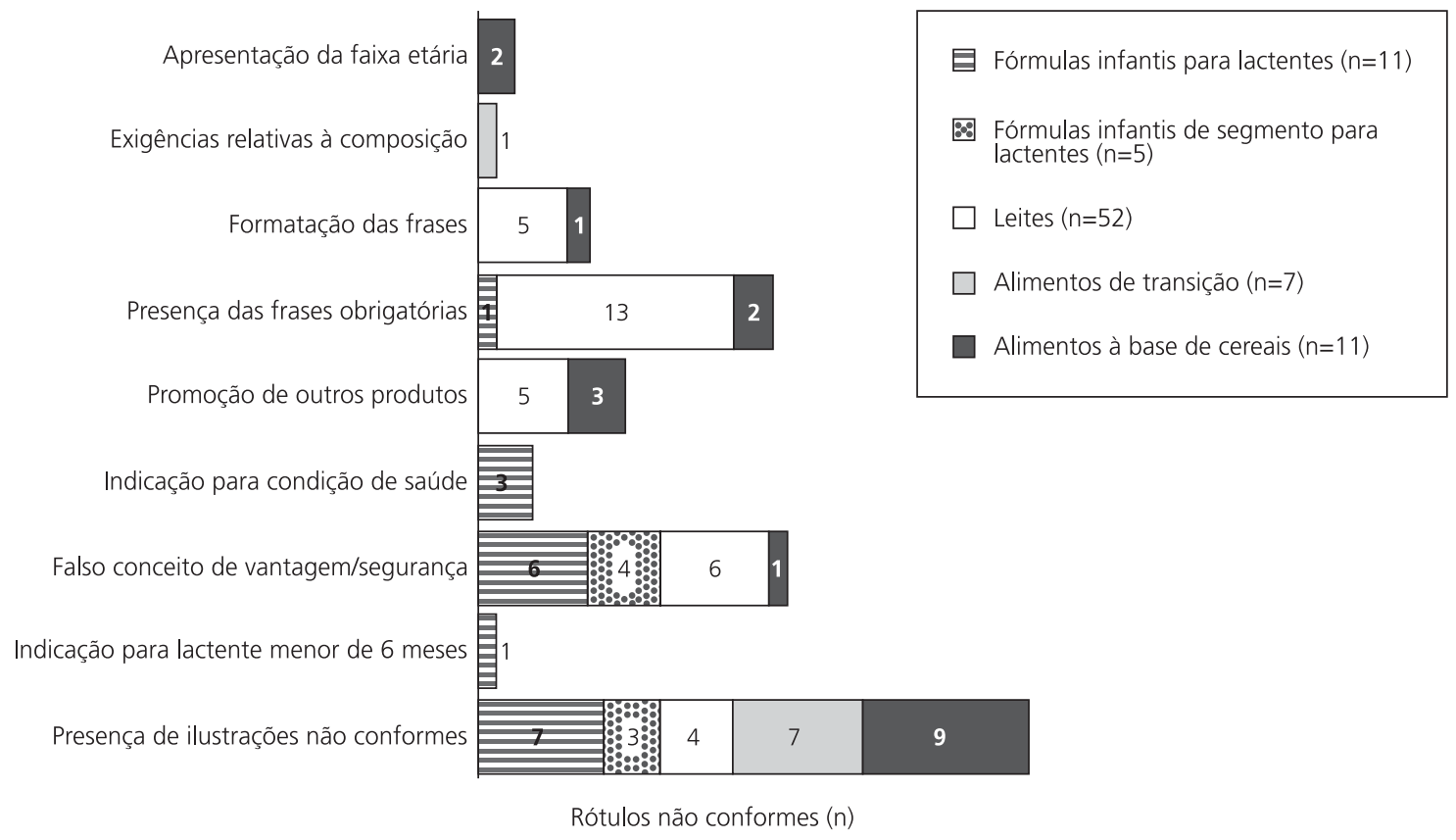

Figura 1. Número de rótulos não conformes em diferentes itens analisados da rotulagem específica de alimentos infantis, por categoria. Goiás, 2004 a 2005. 
e nas fórmulas infantis de seguimento para lactentes (figura independente da marca); ilustrações de crianças de primeira infância, foto de criança aparentando, aproximadamente, 3 anos e personagem infantil nos leites; figura humanizada de ursinho engatinhando ou andando nos rótulos dos alimentos de transição; ilustrações de ursinhos e girafinhas humanizadas nos rótulos de alimentos à base de cereais. As figuras encontradas não podem ser apresentadas por conduzirem à identificação de marcas e empresas, segundo capítulo XII, artigo 22, inciso II, do Código de Ética dos Nutricionistas ${ }^{17}$.

Uma fórmula infantil apresentou a expressão "... é uma fórmula de início para lactentes".

Em relação à exibição de expressões que podem induzir ao uso do produto baseado em falso conceito de vantagem ou segurança, observaram-se as seguintes expressões não conformes:

- Fórmulas infantis para lactentes (item 4.3.1 da Resolução RDC n²22/02): "Contém nutrientes em quantidades adequadas para $\mathrm{O}$ crescimento e desenvolvimento do bebê"; "Contém todas vitaminas e minerais para o desenvolvimento normal do bebê". Outro produto apresentava a expressão "anti-regurgitação".

- Fórmulas infantis de seguimento para lactentes (item 4.3.1 da Resolução RDC $n^{\circ}$ 222/02): "Contém todos os ácidos graxos essenciais para o desenvolvimento normal do lactente"; "Contém nutrientes em quantidades adequadas para o crescimento e desenvolvimento do bebê". Dois produtos apresentaram a expressão "Representa a parte líquida da dieta durante a alimentação de transição".

- Leites (item 4.10.5 da Resolução RDC n 222/02): nesta categoria, observaram-se conceitos de vantagem ou segurança dos tipos falso ou sem comprovação científica. No primeiro caso, com as expressões: "Assegura o crescimento e desenvolvimento saudáveis"; "Crescimento" e "Contém fibras. Melhora a absorção de cálcio, reduzindo riscos de osteoporose". No segundo caso, com as seguintes expressões: "A proteína de soja associada às isoflavonas atua como antioxidante do LDL", "Isoflavonas atuam como antioxidantes" e "Vitamina C aumenta a resistência do corpo às infecções".

- Alimentos à base de cereais (item 4.12.4 da Resolução RDC n 222/02): "Sua fórmula exclusiva possui os ingredientes ideais para o seu filho crescer forte e saudável". "O mingau que ajuda seu filho a crescer".

Quanto à exibição das frases obrigatórias (itens 4.4, 4.11.1, 4.11.2 e 4.14 da Resolução RDC $\left.n^{\circ} 222 / 02^{6}\right)$, observou-se maior número de não conformidades na categoria leites.

Em relação à forma de exibição das frases (itens 4.14 e 4.11 da Resolução RDC n²22/02), foram apresentações não conformes: sem moldura e tamanho diferente da designação de venda; tamanho diferente da designação de venda e sem moldura.

Notou-se que, no caso específico dos leites, muitos apresentavam designação de venda no painel principal, local exigido pela legislação, com letras grandes e a repetiam fora do painel principal com letra pequena do mesmo tamanho das advertências.

Quanto às exigências relativas à composição do produto, um alimento de transição que continha gema de ovo, deveria apresentar a indicação de uso para crianças acima de 10 meses (item 4.1.1 da Portaria $n^{\circ}$ 34/98). No entanto, a indicação apresentada no rótulo era para lactentes acima do sexto mês.

O Teste Qui-Quadrado mostrou que a freqüência de não conformidades/conformidades, na rotulagem específica, se distribui igualmente em relação à rotulagem geral, sem significância estatística. Portanto, aceita-se a hipótese de distribuição homogênea de não conformidades/conformidades entre os dois tipos de rotulagem analisados (Tabela 1). Pelo Teste Exato de Fisher, observou-se que a probabilidade de o número de não conformidades se distribuir igualmente em relação 
à rotulagem geral e à específica, em cada categoria, é significante em quase todas as categorias estudadas, com exceção da subcategoria leites em pó e leites em pó modificados. Esta subcategoria é a única que apresenta freqüências de conformidade iguais em relação à rotulagem específica e à rotulagem geral (Tabela 1).

Observou-se ainda que existe uma correlação significante $(r=0,99)$, ou seja, um alto grau de associação entre o número de produtos comercializados pelas três empresas com maior número de rótulos analisados de todas as categorias, e o número de não conformidades.

\section{Alimentos registrados na categoria Alimentos comuns, mas freqüentemen- te utilizados na alimentação de lactentes ou crianças de primeira infância}

Foram analisados seis mingaus, seis farinhas lácteas e um produto de flocos de cereais. Dos produtos estudados, seis apresentavam figuras e ilustrações de ursinhos, bichinhos e de criança aparentando ter entre 3 a 4 anos. Foram obser-

Tabela 1. Comparação de freqüência de distribuição de não conformidades dos rótulos de alimentação infantil entre rotulagem específica e rotulagem geral, segundo teste aplicado por cada categoria de produtos. Goiás, 2004 a 2005.

\begin{tabular}{lc}
\hline Categoria de alimentos & $\begin{array}{c}\text { Teste exato de } \\
\text { Fisher Valores de } p\end{array}$ \\
\hline Fórmulas infantis de seguimento para & $0,00400^{*}$ \\
lactentes & $0,00029^{*}$ \\
Alimentos de transição & $0,03030^{*}$ \\
Leites de diversas espécies animais & $0,00233^{*}$ \\
Produtos de origem vegetal com & \\
finalidade de leite & 0,27972 \\
Leites em pó e leites em pó modificados & $0,00635^{*}$ \\
Leites de vaca fluidos & Teste Qui-Quadrado \\
Categoria de alimentos & Valores de $\chi^{2}$ \\
Fórmulas infantis para lactentes & 18,33 \\
Leites & 21,67 \\
Alimentos à base de cereais & 121,00 \\
\hline
\end{tabular}

* Valor significante a 5\% de probabilidade. vadas frases que demonstram falso conceito de vantagem ou segurança em quatro produtos: "Vitamina C aumenta a resistência do corpo" e "O mingau para que seu filho cresça e se desenvolva com saúde". Além disso, três produtos traziam no rótulo a promoção de outros alimentos da mesma marca e empresa, o que constitui não conformidade em relação à legislação.

\section{DISCUSS Ã O}

A segunda metade dos anos 90 marcou o processo da conscientização da comunidade científica sobre o seu papel na sociedade fomentando o entendimento e a fiscalização da rotulagem de alimentos adequada, tendo como reflexo a publicação de vários artigos ${ }^{18-22}$.

Esse movimento pode ter influenciado a existência de poucas irregularidades na rotulagem geral dos produtos estudados. Essa freqüência já foi maior na designação de venda de cereais infantis $^{18}$, nos enganos na apresentação das informações nutricionais em queijo petit suisse ${ }^{19}$, em alimentos para dietas com restrição de carboidratos e para dietas de ingestão controlada de açúcares ${ }^{21}$ e em alimentos para praticantes de atividade física ${ }^{22}$.

Yoshizawa et al. ${ }^{18}$ observaram, em 57\% dos alimentos infantis à base de cereais, a ausência da designação de venda. Contudo, no presente trabalho, observou-se que todos os alimentos $(100 \%)$, registrados para lactentes e/ou crianças de primeira infância, apresentaram a designação de venda correta. Estes resultados indicam mudanças positivas, por parte das indústrias, na rotulagem geral desses produtos, provavelmente devido à maior conscientização das mesmas, e pela fiscalização da Agência Nacional de Vigilância Sanitária (ANVISA) e das secretarias estaduais e municipais.

Neste mesmo estudo ${ }^{18}, 28,57 \%$ dos alimentos à base de cereais que continham cacau não apresentavam a advertência de que não devem ser utilizados na alimentação de lactentes 
nos primeiros nove meses de vida. No presente estudo, este item apresentou-se conforme.

O uso de linguagem inadequada em declarações de rotulagem já foi observado pela Comissão Técnica de Avaliação de Alimentos Funcionais do Ministério da Saúde, na avaliação de alegação de propriedade funcional para prebióticos, não aprovando a alegação declarada pela linguagem utilizada22. Posteriormente, o International Baby Food Action Network (IBFAN) identificou esse problema de linguagem como sendo "falso conceito de vantagem e segurança" 23 , expressão utilizada no presente trabalho.

As expressões desse tipo observadas em fórmulas infantis para lactentes, fórmulas infantis de seguimento para lactentes e alimentos à base de cereais, deixam implícito que os referidos produtos são totalmente adequados, completos e que o seu consumo auxilia no crescimento e no desenvolvimento da criança. Deve-se considerar que crescimento e desenvolvimento dependem de muitos outros fatores e não só do consumo de determinado produto.

A expressão "anti-regurgitação", utilizada em outro produto não é correta, pois o leite, sozinho, não resolve o problema de refluxo gástrico. Esta expressão também indica uma condição de saúde, considerada outra não conformidade.

A expressão "Representa a parte líquida da dieta durante a alimentação de transição", apresentada por dois produtos, é inadequada, já que, quando são introduzidos alimentos complementares, a parte líquida é representada não só por leites e produtos lácteos, mas também por sucos e água.

A expressão encontrada em uma fórmula infantil "... é uma fórmula de início para lactentes", pode indicar o produto como apropriado para lactente menor de seis meses, estando em desacordo com o item 4.3.5 da Resolução RDC $n^{\circ} 222 / 02^{6}$, pois se utiliza de informações que possam induzir o uso dos produtos, baseadas em falso conceito de vantagem ou segurança;
As advertências exigidas na rotulagem dos produtos analisados, necessárias e importantes para a promoção do aleitamento materno, acabam perdendo o destaque nos rótulos dos leites pela disposição e tamanho das letras das frases contidas nesses produtos. Isso porque, segundo o item 4.11 da Resolução RDC n²22/02 ${ }^{6}$, as frases de advertências devem vir nos rótulos, no painel principal ou nos demais painéis, em moldura, de forma legível, de fácil visualização, em cores contrastantes, em caracteres idênticos e em mesmo tamanho de letra da designação de venda do produto.

A exigência legal da indicação de uso para crianças acima de 9 meses, em alimentos de transição que contêm ovo, é relevante pela presença, na gema, da proteína fosfitina, que tem a capacidade de se unir ao ferro, diminuindo a sua absorção ${ }^{24}$ e pela probabilidade de, em caso de mal cozimento, favorecer o crescimento da bactéria Salmonella 25 .

O teste de correlação sugere que o número de não conformidades está associado ao número de produtos comercializados pelas grandes marcas deste segmento, ou seja, nas indústrias analisadas, os erros de rotulagem acontecem em todos os produtos da mesma linha.

Apesar de os alimentos comuns analisados serem registrados como tal, percebeu-se que esses produtos direcionam sua rotulagem a lactentes e crianças de primeira infância. No entanto, não se pode afirmar se isso decorre de confusão da própria indústria, não os registrando para o referido público, mas imprimindo, em sua rotulagem, frases de advertência obrigatórias para os produtos registrados; ou se esta é uma prática para escapar das restrições da legislação relacionadas a este seguimento. O risco para a população está na oferta desses produtos para crianças e lactentes de primeira infância, pois possuem as mesmas frases de advertência de outros produtos mais apropriados a este público.

Neste trabalho, no que tange às informações gerais obrigatórias nos rótulos, o direito à informação correta pela população se encontra 
salvaguardado. Entretanto, questões de rotulagem específica ainda se encontram inadequadas, principalmente pelo grande número de produtos que exibem nos seus rótulos ilustrações proibidas e alegações sem embasamento científico e com falso conceito de vantagem ou segurança.

Isso mostra que, embora as regulamentações sobre rotulagem específica para alimentos para lactentes e crianças de primeira infância já existam há alguns anos, a indústria ainda não consegue se comunicar com o consumidor sem ruídos, dificultando, dessa forma, a promoção e a manutenção do aleitamento materno.

Mais estudos são necessários para avaliar o impacto efetivo no consumidor das estratégias de rotulagem de produtos com ou sem designação de venda direcionada a esse público e o impacto na recomendação desses alimentos pelos profissionais de saúde. É preciso também que se conheça a freqüência de consumo pelos lactentes e crianças de primeira infância de mingaus, farinhas lácteas e flocos de cereais registrados como alimentos comuns, mas cuja rotulagem é direcionada a esse público. Além disso, verificar se os cuidadores reconhecem tais alimentos como indicados/adequados à alimentação de lactentes ou crianças de primeira infância.

Com este trabalho, observou-se que as não conformidades na rotulagem específica não ocorrem de forma explícita, como antes. Hoje, estas se dão principalmente pelas ilustrações e linguagens utilizadas que trazem nas entrelinhas a idéia de que o produto é "ideal", "totalmente adequado", "leva ao ótimo crescimento"; ou que é indicado para lactentes e crianças de primeira infância.

\section{O N CLUSÃ O}

Observou-se que, apesar de a regulamentação da rotulagem específica para lactentes e crianças de primeira infância estar cada vez mais rigorosa, as indústrias ainda não se adaptaram a ela, embora o tenham feito em relação à rotula- gem geral. Mesmo as exigências mais importantes, como a obrigatoriedade de exibição das frases de advertência e a proibição de apresentar ilustrações humanizadas de lactentes, são desrespeitadas.

Faz-se importante que os órgãos públicos competentes fiscalizem a rotulagem dos alimentos para lactentes e crianças de primeira infância, tanto no momento do registro quanto no momento da análise de controle. Profissionais de saúde e da área de alimentos, comunidade científica, políticas públicas e, finalmente, os próprios consumidores, devem monitorar as práticas de rotulagem e a promoção comercial desses produtos e, com isto, garantir a amamentação por tempo adequado. A criança amamentada, conforme determinam as normas brasileiras, utilizará menos os serviços públicos de saúde, gerando economia substancial de recursos materiais e humanos.

\section{A GRADECIMENTOS}

A colaboração da Superintendência de Vigilância Sanitária e Ambiental do estado de Goiás, pela aquisição de produtos, e a Juliana Brandstetter Vilar, Professora do Instituto de Ciências Biológicas da Universidade Federal de Goiás, pelo auxílio estatístico.

\section{COLABORADORES}

S.A. SILVA e T.A.P.C. FERREIRA participaram da elaboração de estratégia experimental, da coleta de dados, da tabulação e da discussão dos resultados e da elaboração do artigo. M.R.M. DIAS participou da coleta de dados, da discussão dos resultados e da elaboração do artigo.

\section{REFERÊ NCIAS}

1. Wehba J. Nutrição da criança. São Paulo: Fundo Editorial Byk; 1991.

2. Rea MF. Substitutos do leite materno: passado e presente. Rev Saúde Pública. 1990; 24(3):241-9.

3. Rea MF, Toma TS. Proteção do leite materno e ética. Rev Saúde Pública. 2000; 34(4)388-95.

4. United Nations Children's Fund. International code of marketing of breast milk substitutes. Geneva: World Health Organization; 1981. 
5. World Health Organization. The optimal duration of exclusive breastfeeding. Geneva: World Health Organization; 2001. [cited 2005 Oct 4]. Available from <http://www.who.int/inf-pr-2001/en/note 2001-07.html>.

6. Brasil. Ministério da Saúde. Conselho Nacional de Saúde. Resolução RDC n 31 de 12 de outubro de 1992. Norma brasileira para a comercialização de alimentos para lactentes. [acesso 2004 mar 12]. Disponível em: <www.anvisa.gov.br>

7. Brasil. Ministério da Saúde. Secretaria de Vigilância Sanitária. Resolução RDC $n^{\circ} 222$, de 5 de agosto de 2002. Regulamento técnico para promoção comercial dos alimentos para lactentes e crianças de primeira infância. [acesso 2004 mar 20]. Disponível em: <www.anvisa.gov.br>.

8. Brasil. Ministério da saúde. Portaria n 710 , de 11 de junho de 1999. Programa Nacional de Alimentação e Nutrição. [acesso 2005 dez 6]. Disponível em: <http://ttr2001.saúde.gov.br/portarias/1999.htm>.

9. Brasil. Ministério da Saúde. Secretaria de Vigilância Sanitária. Resolução RDC n 977, de 5 de dezembro de 1998. Regulamento técnico para fórmulas infantis para Lactentes e fórmulas infantis de seguimento. [acesso 2004 mar 14]. Disponível em: $<$ <ww.anvisa.gov.br>.

10. Brasil. Ministério da Saúde. Secretaria de Vigilância Sanitária. Portaria n 34, de 14 de janeiro de 1998. Regulamento técnico de identidade e qualidade de alimentos de transição para lactentes e crianças de primeira infância. [acesso 2004 mar 16]. Disponível em: <www.anvisa.gov.br>.

11. Brasil. Ministério da Saúde. Secretaria de Vigilância Sanitária. Portaria n 36, de 13 de janeiro de 1998. Regulamento técnico de identidade e qualidade de alimentos a base de cereais para alimentação infantil. [acesso 2004 mar 28]. Disponível em: $<$ www.anvisa.gov.br>.

12. Brasil. Ministério da Saúde. Secretaria de Vigilância Sanitária. Resolução RDC $n^{\circ} 40$, de 21 de março de 2001. Regulamento técnico para rotulagem nutricional obrigatória de alimentos e bebidas embalados. [acesso 2004 mar 12]. Disponível em: $<$ <ww.anvisa.gov.br>.

13. Brasil. Ministério da Saúde. Agência Nacional de Vigilância Sanitária. Resolução RDC n²59, de 20 de setembro de 2002. Regulamento técnico para rotulagem de alimentos embalados. [acesso 2004 mar 12]. Disponível em: <www.anvisa.gov.br>.

14. Brasil. Ministério da Saúde. Agência Nacional de Vigilância Sanitária. Resolução $n^{\circ} 23$, de 15 de março de 2000. Manual de procedimentos básicos para registro e dispensa da obrigatoriedade de registro de produtos pertinentes à área de alimentos. [acesso 2004 abr 15]. Disponível em: $<w w w$.anvisa.gov.br>.
15. Brasil. Ministério da Saúde. Agência Nacional de Vigilância Sanitária. Resolução RDC $n^{\circ} 40$, de 8 de fevereiro de 2002. Regulamento técnico para rotulagem de alimentos e bebidas embalados que contenham glúten. [acesso 2004 abr 18]. Disponível em: <www.anvisa.gov.br>.

16. Brasil. Ministério da Saúde. Manual do curso da norma brasileira de comercialização de alimentos para lactentes e crianças de primeira infância, bicos chupetas e mamadeiras. Brasília; 2002.

17. Conselho Federal de Nutricionistas. Resolução n.334 de 10 de maio de 2004. Dispõe sobre o Código de Ética do nutricionista, e dá outras providências. [acesso 2005 fev 25]. Disponível em: <http://www.cfn.org.br/legislacao/resolucao/ res334.htm.>

18. Yoshizawa N, Pospissil RT, Valentim AG, Seixas D, Alves FS, Cassou F, et al. Rotulagem de alimentos como veículo de informação ao consumidor: adequações e irregularidades. Bol Cent Pesqui Process Aliment. 2003; 21(1):169-80.

19. Nunes MCD, Murata LTTF, Alcântara MRS, Germano MIS, Germano PML. Avaliação das sobremesas lácteas: características que podem comprometer a garantia de qualidade. Hig Alimentos. 1998; 12(58):41-8.

20. Araújo ACMF, Araújo WMC. Adequação à legislação vigente da rotulagem de alimentos para fins especiais dos grupos de alimentos para dietas com restrição de carboidratos e alimentos para dieta de ingestão controlada de açúcares. Hig Alimentos. 2001; 15(32):52-70.

21. Borges RF, Sarmento RM, Ferreira TAPC. Conformidade da rotulagem de alimentos para praticantes de atividade física segundo a legislação brasileira. Hig Alimentos. 2005; 19(137):127-35.

22. Lajolo, F.M. Avaliação crítica da legislação e metas alcançadas pela comissão. In: Agência Nacional de Vigilância Sanitária. Alimentos com alegações de propriedades funcionais e de saúde. Brasília: ANVISA, 2001. p.21-44.

23. International Baby Food Action Network. Monitoramento IBFAN Brasil 2004: promoção comercial e rotulagem. [acesso 2005 fev 2]. Disponível em: <www.ibfan.org.br.>.

24. Euclydes MP. Nutrição do lactente: base científica para uma alimentação adequada. 2a. ed. Viçosa: Suprema; 2000.

25. Silvia Júnior, EA. Agentes de doenças transmitidas por alimentos (DTAs). In: Silvia Júnior, EA. Manual de controle higiênico-sanitário em alimentos. 5a.ed. São Paulo: Varela; 1995. p.306-13.

Recebido em: 7/11/2006

Versão final reapresentada em: 30/10/2007 Aprovado em: 29/2/2008 